\title{
Perforating granuloma annulare in children: A case report
}

\author{
Jihane Ziani*, Hanane Baybay, Mounia Bennani, Zakia Douhi, Sara Elloudi and Fatima Zahra Mernissi \\ Department of Dermatology, Hassan II Hospital University, Fez, Morocco
}

\begin{abstract}
Perforating annular granuloma represents $5 \%$ of patients who have an annular granuloma. It is a rare form that rather affects the back of the hand and fingers, it is sometimes generalized on the trunk and extremities. Some lesions are umbilicated (with a hollow in the center) and sometimes allow thick material to flow. The lesions may leave scars that are sequelae. We report an observation in a 7-year-old child.
\end{abstract}

\section{Introduction}

Annulare perforating granuloma (APG) is a rare form of annular granuloma with difficult clinical diagnosis, the confirmation of which is histological. The location is unique in less than $10 \% 100$ of cases. We report a documented case with histological confirmation of annular granuloma florid form and suspicion of APG.

\section{Case presentation}

This is a child aged 7 years, with no notable pathological history, who presented 3 months ago conjunctival hyperemia with a feverish sensation and arthralgia preceding the installation of erythematous lesions for certain painful nonpruritic pain increasing gradually of size becoming pustular sitting on the level of the members having been then of the face and the mucous membranes associated with digestive signs. The examination on admission objectified an apyrexia with a conservation of the general state and multiple erythematous papules certain flesh color slightly painful surmounted by follicular pustules by place sitting at the level of the faces of extensions of the members and acrale, as well as of the face with conjunctival hyperemia, nasal erosion, cheilitis, similar lesions in the peri-scrotal, and anitis. Multiple scarred pigmented macules with cup-like appearance in places. In biology; no inflammatory syndrome with correct leukocytes, normal VS and CRP, a priori a table of vasculitis was mentioned, an anatomopathological study on skin biopsy made it possible to make the diagnosis of annular granuloma with all the histological elements which were in favor (Figure 1).

\section{Discussion}

The classic clinical presentation of GA is that of a moderately erythematous papule which tends to extend into a plate with a raised border [1]. Perforating GA was first reported by Owens and Freeman in 1971 [2], and corresponds to a fairly rare form, estimated at $5 \mathrm{p}$. 100 of GA [3]. Clinically, perforating GA lesions, sometimes itchy or painful, affect all parts of the body but especially the extension faces of the limbs, the dorsal side of the hands and the fingers. Perforating GA lesions develop in 4 stages: erythematous or flesh-colored papules, then pustular lesions from which flows a thick, creamy or clear and viscous material, which evolves into umbilicated or crusted papules then in hypo or hyperpigmented atrophic scars. However, some of the

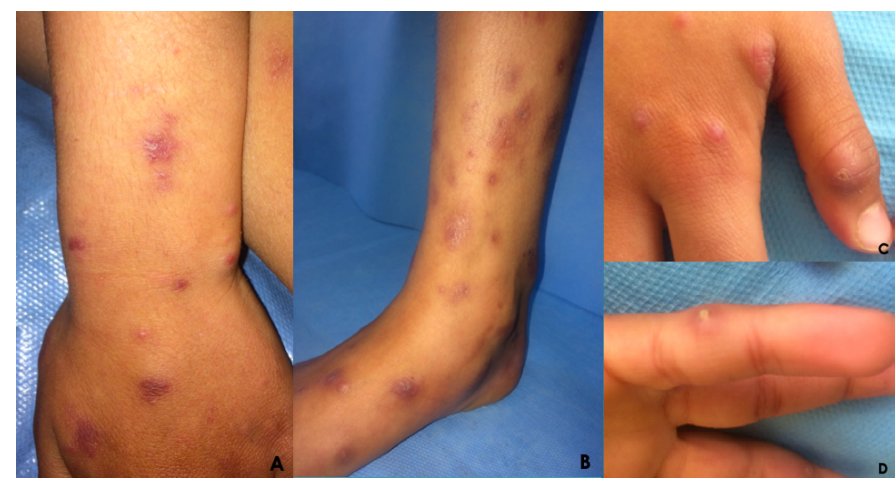

Figure 1. A. Erythematous papules on the posterior aspect of the right forearm. B Pigmented scar macules with a cup-like appearance in places. Chair C. Colored papule sitting at the dorsal surface of the right thumb surmounted by a crust. D. Erythematous papule surmounted by a pustule at the level of the left index finger

lesions do not perforate, while others heal without scars [1]. Regarding spontaneous evolution and treatment, the study by Penas et al. [2] showed spontaneous remission of the lesions in 77 p. 100 of patients in 3 to 4 years. Treatment of asymptomatic lesions therefore does not seem necessary. Different treatments have been used with varying success: local or intralesional corticosteroids, cryotherapy and surgery and, in disseminated forms, PUVA therapy, oral isotretinoin [4], oral corticosteroids, chloroquine, hydroxychloroquine [5], dapsone and potassium iodide.

\section{Conclusion}

Annulare granuloma has long been considered a reaction to a large number of toxic conditions or agents in people. At present, despite the progress of histochemical studies and electron microscopy, the etiology remains unknown and several pathogenic hypotheses are advanced.

${ }^{\star}$ Correspondence to: Jihane Ziani, Department of Dermatology, Hassan II Hospital, University, Fez, Morocco, E-mail: dr.zianijihane@gmail.com

Key words: annulare perforating granuloma, children

Received: Mar 02, 2020; Accepted: May 09, 2020; Published: May 16, 2020 


\section{References}

1. Billet A, Viseux V, Chaby G, Dascotte-Barbeau E, Gontier MF, et al. (2015) Perforating granuloma annulare with transfollicular perforation. Ann Dermatol Venereol 132: 678681

2. Owens DW, Freeman RG (1971) Perforating granuloma annulare. Arch Dermatol 103: 64-67.
3. Penas PF, Jones-Caballero M, Fraga J, Sanchez-Perez J, Garcia-Diez A (1997) Perforating granuloma annulare. Int J Dermatol 36: 340-348. [Crossref]

4. Ratnavel RC, Norris PG (1995) Perforating granuloma annulare: Response to treatment with isotretinoin. J Am Acad Dermatol 32: 126-127. [Crossref]

5. Jackson MD, Pratt L, Lawson P (2001) Asymptomatic papules on a child. Perforating granuloma annulare. Arch Dermatol137: 1647-1652. [Crossref]

Copyright: @2020 Ziani J. This is an open-access article distributed under the terms of the Creative Commons Attribution License, which permits unrestricted use, distribution, and reproduction in any medium, provided the original author and source are credited. 